\title{
Youth Labour Flows and Unemployment in Great Recession: Comparing Spain and the Czech Republic
}

\author{
Vladislav Flek, Martina Mysíková ${ }^{1}$
}

\begin{abstract}
Using Spain and the Czech Republic as examples of two EU countries with different labour market performance, we apply a gross flow analysis based on EU-SILC longitudinal data. We find that while in Spain the increases in youth unemployment are driven mostly by young people who lose their jobs, in the Czech Republic, this is mainly due to new labour market entrants who failed to find a job. The analysis of flow transition rates suggests that youth labour markets with enormously high unemployment rates have not failed in all relevant respects. Their development seems to be hindered predominantly by high risk of job losses and diminishing employment prospects of the unemployed, rather than by impeded transitions from inactivity to employment. In countries with lower youth unemployment rates, unemployment policy agenda appears to be challenged by quite the opposite tendency.
\end{abstract}

Key words: Flow transition rates, Gross labour market flows, Unemployment

JEL Classification: E24, J60

\section{Introduction}

Many observers attempt to explain why young people suffer relatively more from unemployment. As shown by e.g. Quintini and Manfredi (2009); McGuinness and Wooden (2009); Blanchflower and Bell (2011); or ILO (2013), only a fraction of schoolleavers and university graduates immediately manage to find a stable and satisfactory job. The rest is first faced with unemployment, or frequent job changes combined with the incidence of repeated unemployment spells. This situation is often attributed to educational mismatch on youth labour markets, to lack of work experience and to absence of firm-specific skills. In addition to that, jobs held by young people tend to be less stable even when education, skills and other characteristics match the employer's requirements. Young employees are still more likely to be affected by layoffs, for in-

\footnotetext{
${ }^{1}$ Metropolitan University Prague, Center for European Economic and Social Studies (CEESS), Prokopova 16, 13000 Prague 3, Czech Republic. Work on this paper has benefited from funding from the European Union's 7th Framework Programme (Grant Agreement no. 613256, project name: "Strategic Transitions for Youth Labour in Europe"). EU-SILC data were made available to the authors on the basis of contract no. EU-SILC/2012/66 between the European Commission, Eurostat, and Metropolitan University Prague. Our thanks are due to Martin Hála, Seamus McGuinness, Pavel Mertlík, Jiří Večerník, Pavlína Žáková and two anonymous referees for their helpful comments. However, the authors alone remain responsible for the results.

Email: vladislav.flek@mup.cz; martina.mysikova@mup.cz.
} 
stance, because of the frequent practice of fixed-term labour contracts, the existence of seniority-weighted redundancy payments or last-in first-out rules. Great Recession has further amplified the already existing difficulties of young people on the labour market, a situation which results in disproportionate increases in youth unemployment (Blanchflower and Bell, 2011; ECB, 2012).

A view offered in this paper is based on a flow approach, with the main focus on the following questions: How does the labour market dynamics, expressed by movements (gross flows) of young people between employment, unemployment and inactivity, differ from the dynamics among prime-age individuals? How does each of these movements shape the evolution of youth and prime-age unemployment? Do the most marked differences between young and prime-age individuals lie in chances to retain jobs, in probability of exiting unemployment, or in transitions between inactivity and labour market? Are the differences noted above typical for certain educational or gender group? And how did they evolve as the Great Recession deepened? In this paper we aspire on answering such questions for Spain and the Czech Republic in 2007-2010.

Despite the substantial differences in unemployment rates, size of the two labour markets, institutional design, demographic developments, educational systems and applied policies, youth unemployment rates in both countries approximately doubled during that period, while the upward aggregate (prime-age) unemployment rate evolutions were comparatively less rapid. Thus, youth unemployment is gaining in policy relevance for both countries. In our opinion, comparing Spain and the Czech Republic makes sense since the proposed comparison can reveal what type of labour market dynamics is typical for high/low unemployment countries in European Union, and how do they differ in terms of appropriate policy action.

For instance, we intend to show that increasing unemployment can be a result of different relative contributions of particular gross flows. To maximise its impact, any policy action aimed at unemployment reductions has to be structured accordingly. As noted explicitly by Elsby et al. (2011, p. 4) „... policy that focused on encouraging outflows from unemployment may not be as relevant in an economy in which rises in unemployment were driven by...outflows from employment." Moreover, it is far from obvious that youth (prime-age) labour markets with enormously high unemployment rates have failed in all relevant respects. It is more likely that their problems are concentrated in some particular areas while in others they may perform equally well or even better than low unemployment countries. Our analysis of transitional probabilities of moving from one labour market status to another intends to identify such areas.

European flow analyses typically concern working-age population as a whole rather than the young and their sub-groups. Elsby et al. (2011) is one of the few exceptions known to us, who deal explicitly with the flows of young people in the UK. In addition, the existing flow literature often lacks international dimension and/or longitudinal structure because of data limitations (Burda and Wyplosz, 1994; Bellmann et al., 1995; Gomes, 2009). In the next section we attempt to propose how to conduct international flow analyses by using the recent longitudinal micro data available from Statistics on Income and Living Conditions (EU-SILC). These data are then used for analysis in the sections to follow. It follows that our approach is relatively new in terms of employing international longitudinal data and in the focus on youth unemployment. That is also 
why we are considerably limited in comparisons of our results with the existing literature.

First, we deal with age-specific movements between employment, unemployment and inactivity. In literature, such movements are usually referred to as gross flows, and serve as a proxy for measuring labour market fluidity (Blanchard and Diamond, 1990). Additionally, the flow analysis enables us to demonstrate how do movements of people in and out of unemployment account for changes in unemployment rates (Dixon et al. 2011), and to point to possible systematic differences between young and prime-age individuals. A related approach applied later in the text focuses on flow transition rates (transition probabilities) of moving between the three labour market states - employment, unemployment and inactivity (Blanchard and Diamond, 1990; Gomes 2009; Silverstone and Bell, 2010; Elsby et al. 2011; ECB 2012). Here we intend to account for possible differences between individual labour market prospects of young workers of both genders and education. Last section concludes.

\section{The Data}

EU-SILC is an annual survey with retrospectively stated economic activity in the previous calendar year. ${ }^{2}$ It is harmonized by Eurostat and its longitudinal version is designed as a four-year rotational panel. The longitudinal character of the survey makes it possible to identify each respondent's labour market status and its changes on monthly basis. The survey also contains a set of additional variables relevant for our purposes, such as age, gender and education. Monthly information on labour market status can potentially minimize the time aggregation bias which is inherently present in longitudinal analyses, e.g. European Union Labour Force Survey (EU-LFS) with its quarterly structure of information. The practical possibility of conducting international comparative analyses of labour market flows is another advantage of longitudinal EU-SILC. The use of longitudinal EU-LFS for international comparative analyses still remains considerably limited since it is not routinely available for research purposes. ${ }^{3}$

As a result, the use of longitudinal EU-SILC appears to be the only practically accessible way of how to conduct our analysis, in spite of its potential drawbacks, the retrospective nature of reported economic activity and its self-declared character among others. This may also lead to departure from the ILO definition of unemployment. Moreover, the structure of the survey makes is impossible to analyse direct job-to-job flows of respondents.

\footnotetext{
${ }^{2}$ Employment definition in EU-SILC includes employees and self-employed (including family workers) working part-time or full-time. Unemployment is self-defined according to person's own perception. Inactivity comprises students, further training, unpaid work experience, retirement and early retirement, permanently disabled, military service, fulfilling domestic tasks and care responsibilities, and other inactive persons.

${ }^{3}$ The flow analysis of ECB (2012) stresses explicitly the limited availability/reliability of EU LFS data.
} 
A natural option would be to make use of the most recent full four-year panel of EUSILC 2011 and thus fully exploit the longitudinal element of EU-SILC. For a period 1/2007-12/2010 it provides a chain of 47 monthly individual comparisons of the previous and current labour market statuses. However, we are particularly interested in a group of young individuals, namely in those aged 16-24 at the beginning of the analysed period, which rules out the possibility to utilise the full four-year panel data due to its small number of respondents.

Instead, we decided to extract two two-year periods from EU-SILC 2009, which covers the monthly economic activity for 1/2007-12/2008, and EU-SILC 2011, which involves the period 1/2009-12/2010. Both of these subsamples provide chains of 23 monthly comparisons of individual labour market statuses and contain substantially more respondents than the full four-year panel. As the reference group prime-age population aged between 25 and 54 at the beginning of both analysed periods was selected. Only those respondents of both age categories who had fully participated in these two-year surveys were subjects of further analysis. Thus our two subsamples (2007-2008, 20092010) can be viewed as pure two-year panels, where all the reported month-to-month individual labour market statuses are matched.

Our pre-weighted matched subsamples eventually consist of 1,757 and 1,560 young Czechs and 2,391 and 2,271 young Spanish for the respective periods. The other groups include 6,554 and 5,655 Czech, and 10,198 and 9,929 Spanish prime-aged workers. Afterwards we applied the longitudinal weights designed by Eurostat specifically for these two-year subsamples, the standard means of minimising the possible attrition bias.

\section{Gross Labour Market Flows and Unemployment}

The analysis of gross labour market flows presented in this section enables us to establish which flows are crucial for the entire labour market dynamics, which are comparable in size, and which are just of minor importance. Then we shall proceed with an analysis of the link between gross flows and unemployment to identify the key drivers of unemployment dynamics.

\section{Gross Flows between Employment, Unemployment and Inactivity}

The calculation of gross flows involves the number of individuals entering the labour market from previous inactivity $\left(I_{t-1}\right)$ and moving either into employment $\left(E_{t}\right)$ or unemployment $\left(U_{t}\right)$. It also captures those who leave employment $\left(E_{t-1}\right)$ and move either into unemployment $\left(U_{t}\right)$ or inactivity $\left(I_{t}\right)$. Finally, there are people exiting unemployment $\left(U_{t-1}\right)$ and moving either into employment $\left(E_{t}\right)$ or inactivity $\left(I_{t}\right)$. This gives us the following six gross flows, expressed as the number of individuals moving between the previous and current labour market statuses: $\left(E_{t-1} \rightarrow U_{t}\right) ;\left(E_{t-1} \rightarrow I_{t}\right) ;\left(U_{t-1} \rightarrow\right.$ $\left.E_{t}\right) ;\left(U_{t-1} \rightarrow I_{t}\right) ;\left(I_{t-1} \rightarrow E_{t}\right) ;\left(I_{t-1} \rightarrow U_{t}\right)$. In turn, the number of those who maintain their previous labour market status can be expressed as $\left(E_{t-1} \rightarrow E_{t}\right) ;\left(U_{t-1} \rightarrow U_{t}\right)$; $\left(I_{t-1} \rightarrow I_{t}\right)$.

Our weighted matched samples involve 23 monthly observations of gross labour market flows for the periods 2007-2008 and 2009-2010. Based on this information, the average monthly numbers of individuals involved in each of the six gross flows or remain- 
ing in the previous labour market status can be calculated for each country, period and age group of interest. However, in order to compare the importance of each gross flow for the entire labour market dynamics, it is more illustrative to analyse the relative figures. In other words, the number of people involved in a particular gross labour market flow has to be divided by the total number of matched labour market stocks. In Table 1 , $U E=\left(U_{t-1} \rightarrow E_{t}\right) /\left(E_{t-1}+U_{t-1}+I_{t-1}\right)$ indicates the proportion of young (prime-age) individuals involved, on average, every month in a gross flow from unemployment to employment, and so on for EU, EI etc.

The bottom row in Table 1 reveals differences in the relative involvement of young and prime-age individuals in gross labour market flows. It shows that young workers are relatively more often involved in labour market flows than their prime-age counterparts. This finding holds across the countries and periods analysed and confirms the observations of Elsby et al. (2011), who also found that young people "churn" trough the labour markets relatively more frequently.

Table 1 Gross Labour Market Flows in Spain and the Czech Republic

\begin{tabular}{|c|c|c|c|c|c|c|c|c|}
\hline \multirow{2}{*}{$\begin{array}{l}\text { Flow } \\
\downarrow \quad \text { share } \\
\end{array}$} & \multicolumn{4}{|c|}{ ES } & \multicolumn{4}{|c|}{$\mathrm{CZ}$} \\
\hline & \multicolumn{2}{|c|}{ 2007-2008 } & \multicolumn{2}{|c|}{ 2009-2010 } & \multicolumn{2}{|c|}{ 2007-2008 } & \multicolumn{2}{|c|}{ 2009-2010 } \\
\hline age $\rightarrow$ & youth & prime & youth & prime & youth & prime & youth & prime \\
\hline$E U$ & 0.96 & 0.86 & 0.77 & 0.93 & 0.18 & 0.25 & 0.31 & 0.35 \\
\hline$E I$ & 0.55 & 0.12 & 0.35 & 0.11 & 0.12 & 0.16 & 0.09 & 0.17 \\
\hline$U E$ & 0.80 & 0.67 & 0.68 & 0.85 & 0.36 & 0.36 & 0.45 & 0.38 \\
\hline$U I$ & 0.08 & 0.05 & 0.20 & 0.08 & 0.05 & 0.05 & 0.08 & 0.04 \\
\hline$I E$ & 0.93 & 0.12 & 0.51 & 0.11 & 0.53 & 0.18 & 0.27 & 0.18 \\
\hline$I U$ & 0.29 & 0.07 & 0.24 & 0.08 & 0.21 & 0.07 & 0.36 & 0.07 \\
\hline Total & 3.61 & 1.89 & 2.75 & 2.16 & 1.45 & 1.07 & 1.56 & 1.19 \\
\hline
\end{tabular}

Note: $\quad$ Monthly averages; in per cent of matched labour market stocks of young and prime-age individuals.

Source: EU-SILC LONGITUDINAL UDB 2009, version 4 of March 2013; EU-SILC LONGITUDINAL UDB 2011, version 1 of August 2013. Own calculations from weighted matched samples.

The figures in Table 1 enable us also to categorise the relative importance of each of six gross flows for the entire labour market dynamics and to compare the results of the young and prime-age individuals. In line with expectations, labour market dynamics of prime-age individuals is concentrated predominantly in gross flows between employment and unemployment and vice versa. In contrast, the patterns of youth labour market dynamics are much more dispersed, with relatively higher gross flows into and from inactivity compared to prime-age individuals. The distinctive features of the youth and prime-age labour market dynamics are most remarkable when comparing the relative share of individuals involved in gross flows from inactivity to unemployment $(I U)$ and from inactivity to employment (IE) of both age groups. 


\section{Gross Flows and Net Change in Unemployment}

Conventionally, changes in the number of unemployed $(\Delta U)$ can be expressed as the first difference between unemployment stocks at times $t$ and $(t-1)$. However, following the flow literature, we express $(\Delta U)$ as a balance of gross flows "in" and "out" of unemployment:

$$
\Delta U=[\underbrace{\left(E_{t-1} \rightarrow U_{t}\right)+\left(I_{t-1} \rightarrow U_{t}\right)}_{\mathrm{IN}}]-[\underbrace{\left(U_{t-1} \rightarrow I_{t}\right)+\left(U_{t-1} \rightarrow E_{t}\right)}_{\text {OUT }}]
$$

Formula (1) and Tables $2-3$ clarify how gross flows shape the evolution of unemployment. The observed net changes in the number of unemployed result from the surprisingly high amount of people either entering or leaving the unemployment status. This finding is valid, albeit with different intensity, for all the countries, periods and age groups analysed. For instance, average monthly net increase in prime-age (youth) unemployment recorded for Spain in 2009-2010 is 17,264 (5,195) people. But there are $373,820(81,355)$ individuals who move, on average, every month into or from unemployment.

In more detail, on average 195,542 (43,275) Spanish workers become unemployed every month, and 178,278 $(38,080)$ find a job. Thus unemployment is in general much less stable phenomena than one would consider when looking solely at figures based on unemployment stocks. Among other findings, the second column of Table 2 documents that in absolute numbers the major source of increasing youth unemployment in Spain is clearly the gross flow into unemployment from employment $\left(E_{t-1} \rightarrow U_{t}\right)$. In direct contrast, Table 3 in its third column testifies that the increase in the number of young unemployed in the Czech Republic is mainly due to inflows of new labour market entrants into unemployment $\left(I_{t-1} \rightarrow U_{t}\right)$.

Thus, in addition to different youth unemployment figures in absolute numbers, there are also remarkable cross-country differences in the key drivers of increases in the total number of youth unemployed. Furthermore, Table 3 suggests the presence of serious adverse tendencies also on the Czech youth labour market. Such a message still remains rather hidden behind the relatively favourable aggregate figures. Nonetheless, in 20092010, nearly 90 per cent of monthly unemployment increases displayed in Table 3 are to be attributed to Czech youth, compared to only 23 per cent in Spain. Viewed from this perspective, youth unemployment in the Czech Republic is a much more disproportionate phenomenon than in Spain. 
Table 2 Gross Labour Market Flows and Unemployment in Spain (in absolute numbers, monthly averages)

\begin{tabular}{crrrrrrrr}
\hline & IN-OUT & $\begin{array}{c}\left(E_{t-1}\right. \\
\left.\rightarrow U_{t}\right)\end{array}$ & $\begin{array}{l}\left(I_{t-1}\right. \\
\left.\rightarrow U_{t}\right)\end{array}$ & \multicolumn{1}{c}{ IN } & $\begin{array}{r}\left(U_{t-1}\right. \\
\left.\rightarrow E_{t}\right)\end{array}$ & $\begin{array}{r}\left(U_{t-1}\right. \\
\left.\rightarrow I_{t}\right)\end{array}$ & OUT & IN+OUT \\
\hline 2007-2008 & & & & & & & & \\
prime-age & 39,324 & 162,967 & 12,402 & 175,369 & 126,902 & 9,143 & 136,045 & 311,414 \\
youth & 15,963 & 40,932 & 12,141 & 53,073 & 33,830 & 3,280 & 37,110 & 90,183 \\
total & 55,287 & 203,899 & 24,543 & 228,442 & 160,732 & 12,423 & 173,155 & 401,597 \\
\% of youth & 28.90 & 20.10 & 49.50 & 23.20 & 21.05 & 26.50 & 21.40 & 22.40 \\
\hline 2007-2008 & & & & & & & & \\
prime-age & 17,264 & 179,286 & 16,256 & 195,542 & 162,856 & 15,422 & 178,278 & 373,820 \\
youth & 5,195 & 33,070 & 10,205 & 43,275 & 29,294 & 8,786 & 38,080 & 81,355 \\
total & 22,459 & 212,356 & 26,461 & 238,817 & 192,150 & 24,208 & 216,358 & 455,175 \\
\% of youth & 23.10 & 15.60 & 38.60 & 18.10 & 15.20 & 36.30 & 17.60 & 17.90 \\
\hline
\end{tabular}

Table 3 Gross Labour Market Flows and Unemployment in the Czech Republic (in absolute numbers, monthly averages)

\begin{tabular}{crrrrrrrr}
\hline & IN-OUT & $\begin{array}{c}\left(E_{t-1}\right. \\
\left.\rightarrow U_{t}\right)\end{array}$ & $\begin{array}{l}\left(I_{t-1}\right. \\
\left.\rightarrow U_{t}\right)\end{array}$ & \multicolumn{1}{c}{ IN } & $\begin{array}{r}\left(U_{t-1}\right. \\
\left.\rightarrow E_{t}\right)\end{array}$ & $\begin{array}{r}\left(U_{t-1}\right. \\
\left.\rightarrow I_{t}\right)\end{array}$ & OUT & IN+OUT \\
\hline 2007-2008 & & & & & & & & \\
prime-age & $-4,183$ & 10,849 & 2,987 & 13,836 & 15,648 & 2,371 & 18,019 & 31,855 \\
$\quad$ youth & -176 & 2,071 & 2,345 & 4,416 & 4,073 & 519 & 4,592 & 9,008 \\
$\quad$ total & $-4,359$ & 12,920 & 5,332 & 18,252 & 19,721 & 2,890 & 22,611 & 40,863 \\
\% of youth & 4.00 & 16.00 & 44.00 & 31.90 & 20.60 & 18.00 & 20.30 & 22.00 \\
\hline 2007-2008 & & & & & & & & \\
prime-age & 253 & 15,349 & 3,161 & 18,510 & 16,555 & 1,702 & 18,257 & 36,767 \\
youth & 1,643 & 3,554 & 4,155 & 7,709 & 5,172 & 894 & 6,066 & 13,775 \\
total & 1,896 & 18,903 & 7,316 & 26,219 & 21,727 & 2,596 & 24,323 & 50,542 \\
\% of youth & 86.70 & 18.80 & 56.80 & 29.40 & 23.80 & 34.40 & 24.90 & 27.20 \\
\hline
\end{tabular}

Tables 2 and 3 notes: $\Delta U=I N-O U T=$ Net change in Unemployment $;\left(E_{t-1} \rightarrow U_{t}\right)=$ Inflows into unemployment from employment; $\left(I_{t-1} \rightarrow U_{t}\right)=$ Inflows into unemployment from inactivity; $\left(U_{t-1} \rightarrow E_{t}\right)=$ Outflows from unemployment into employment; $\left(U_{t-1} \rightarrow I_{t}\right)=$ Outflows from unemployment into inactivity.

Source of Tables 2 and 3: EU-SILC LONGITUDINAL UDB 2009, version 4 of March 2013; EUSILC LONGITUDINAL UDB 2011, version 1 of August 2013. Own calculations from weighted matched samples. 


\section{Gross Flows and Unemployment Rate Dynamics}

It is evident from formula (1) that $U_{t}=\Delta U+U_{t-1}=(I N-O U T)+U_{t-1}$, and a change in the unemployment rate can be expressed as follows:

$$
\begin{gathered}
\Delta\left(\frac{U}{L F}\right)=\frac{(I N-O U T)}{L F_{t}}+\frac{U_{t-1}}{L F_{t}}-\frac{U_{t-1}}{L F_{t-1}} \\
=\frac{(I N-O U T)}{L F_{t}}+U_{t-1}\left(\frac{1}{L F_{t}}-\frac{1}{L F_{t-1}}\right) \\
\Delta\left(\frac{U}{L F}\right)=\underbrace{\frac{\left(E_{t-1} \rightarrow U_{t}\right)+\left(I_{t-1} \rightarrow U_{t}\right)}{L F_{t}}}_{I N}-\underbrace{\frac{\left(U_{t-1} \rightarrow E_{t}\right)+\left(U_{t-1} \rightarrow I_{t}\right)}{L F_{t}}}_{\text {OUT }} \\
+\underbrace{U_{t-1}\left(\frac{1}{L F_{t}}-\frac{1}{L F_{t-1}}\right)}_{L F}
\end{gathered}
$$

If $(I N-O U T)=0$, then the number of unemployed remains constant over time. In such a case, the observed changes in unemployment rate are to be attributed solely to a changing labour force. ${ }^{4}$ Conversely, under constant labour force, unemployment rate changes would be driven solely by net changes in unemployment. ${ }^{5}$

Table 4 documents the disproportionate developments in youth unemployment rates compared to evolutions in prime-age unemployment rates. This applies fully to Spain, where the upward youth unemployment rate dynamics is higher for both 2007-2008 and 2009-2010. In the Czech Republic, similar developments are apparent only in the second period analysed. Table 4 also indicates contributions to unemployment rate dynamics recorded for both age categories. In general, the "ins" and "outs" of unemployment account for virtually 100 per cent of changes in prime-age unemployment rates. The structure of youth unemployment rate dynamics is different due to non-negligible contributions of changes in the youth labour force. Yet the "ins" and "outs" remain decisive for identifying the sources of different evolutions in the youth- and prime-age unemployment rates.

\footnotetext{
${ }^{4}$ A negative sign of the third term on the RHS of formula (3) indicates a decline in percentage points in the unemployment rate due to increasing labour force. Contribution of changes in labour force to changes in the unemployment rate can further be decomposed (Dixon et al. 2011), but for the sake of simplicity we limit our analysis to decompositions expressed in our formula (3).

${ }^{5}$ Formula (3) is based, with certain modifications, on Dixon et al. (2011). A more common practice is to show how much of the variance of the steady state unemployment rate accounts for changes in the flow transition rates. Elsby et al. (2011) use this approach for analysing the youth unemployment. Following credibly this research direction requires to analyse longer time periods, and is therefore beyond the scope of the present analysis.
} 
Table 4 Unemployment Rates Dynamics - Flow Decomposition (monthly averages, in p.p.)

\begin{tabular}{|c|c|c|c|c|c|c|c|c|}
\hline $\begin{array}{l}\text { Period/ } \\
\text { country }\end{array}$ & $\Delta\left(\frac{U}{L F}\right)$ & $\begin{array}{l}\text { Contri- } \\
\text { bution of } \\
\text { IN }\end{array}$ & $\frac{\left(E_{t-1} \rightarrow U_{t}\right)}{L F_{t}}$ & $\frac{\left(I_{t-1} \rightarrow U_{t}\right)}{L F_{t}}$ & $\begin{array}{l}\text { Contri- } \\
\text { bution of } \\
\text { OUT }\end{array}$ & $\frac{\left(U_{t-1} \rightarrow E_{t}\right)}{L F_{t}}$ & $\frac{\left(U_{t-1} \rightarrow I_{t}\right)}{L F_{t}}$ & $\begin{array}{c}\text { Contri- } \\
\text { bution of } \\
\text { changing } \\
\text { LF }\end{array}$ \\
\hline \multicolumn{9}{|l|}{ 2007-08 } \\
\hline$E S$ & & & & & & & & \\
\hline - youth & 0.5598 & 2.6376 & 2.0342 & 0.6034 & -1.8443 & -1.6813 & -0.1630 & -0.2335 \\
\hline $\begin{array}{l}- \text { p.a. } \\
C Z\end{array}$ & 0.2262 & 1.0181 & 0.9461 & 0.0720 & -0.7898 & -0.7367 & -0.0531 & -0.0021 \\
\hline - youth & -0.2994 & 1.1077 & 0.5194 & 0.5882 & -1.1517 & -1.0215 & -0.1302 & -0.2554 \\
\hline - p.a. & -0.1131 & 0.3672 & 0.2879 & 0.0793 & -0.4782 & -0.4153 & -0.0629 & -0.0020 \\
\hline \multicolumn{9}{|l|}{$\begin{array}{l}\text { 2009-10 } \\
E S\end{array}$} \\
\hline - youth & 0.1230 & 2.5633 & 1.9588 & 0.6045 & -2.2556 & -1.7352 & -0.5204 & -0.1847 \\
\hline $\begin{array}{l}- \text { p.a. } \\
C Z\end{array}$ & 0.1004 & 1.1302 & 1.0362 & 0.0940 & -1.0304 & -0.9413 & -0.0891 & 0.0006 \\
\hline - youth & 0.0918 & 2.1236 & 0.9790 & 1.1446 & -1.6710 & -1.4248 & -0.2463 & -0.3608 \\
\hline - p.a. & 0.0025 & 0.4855 & 0.4026 & 0.0829 & -0.4788 & -0.4342 & -0.0446 & -0.0042 \\
\hline
\end{tabular}

Let us illustrate this point in more detail by looking at the situation in Spain in 20072008. It can be concluded from Table 4 that the monthly youth unemployment rate in Spain in 2007-2008 grew on average more than twice as fast as the prime-age unemployment rate. What are the sources of this disproportionality? First, let us concentrate on the "ins" and "outs" of unemployment in Spain during that period. Such a view would provide a closer look at age-specific unemployment rate dynamics, net of changes in labour force. In this respect, the most striking difference concerns the gross flows into unemployment $\left(E_{t-1} \rightarrow U_{t} ; I_{t-1} \rightarrow U_{t}\right)$.

For young individuals in Spain in 2007-2008, the sum of these two "ins" accounts on average for 2.6 percentage points of increase in the monthly youth unemployment rate. The respective contribution of the "ins" to increases in prime-age unemployment rate represents just one percentage point. The major part of this difference is concentrated in the gross flow from employment into unemployment $\left(E_{t-1} \rightarrow U_{t}\right)$. The monthly youth unemployment rate was increasing on average by two percentage points due to this gross flow compared to less than one percentage point of increase in the prime-age unemployment rate.

When looking at the "outs" of youth unemployment in Spain in the same period $\left(U_{t-1} \rightarrow E_{t} ; U_{t-1} \rightarrow I_{t}\right)$, they accounted on average for a monthly youth unemployment rate decline of 1.8 percentage points. The contribution of the "outs" to diminishing the prime-age unemployment rate was one percentage point lower. Nevertheless, the total balance of "ins" and "outs" remained highly unfavourable for Spanish youth. 
When taking into account the changes in youth labour force in Spain over 2007-2008, the overall picture does not change dramatically. Although the increases in youth labour force diminished their monthly average unemployment rate by some 0.25 percentage points, this was clearly not enough to offset the adverse balance between the "ins" and "outs" of youth unemployment. In principle, the patterns of unemployment dynamics in Spain did not change in 2009-2010 either, although the increases in youth and primeage unemployment rates converged remarkably.

When compared to Spain, the situation of young people on the Czech labour market looks almost idyllic at first glance. However, the period 2009-2010 was in fact marked with strong relative deterioration in youth unemployment in the Czech Republic. While, on average, the monthly prime-age unemployment rate stagnated during that period, the youth unemployment rate was increasing every month on average by some 0.1 percentage point. As shown in the previous subsection, if we consider the youth and prime-age individuals together, Czech young people accounted for about 90 per cent of net increases in the number of unemployed in 2009-2010.

As with Spain, the "ins" were the major adverse factor influencing the disproportionate upward dynamics of the youth unemployment rate. Specifically, the gross flows into unemployment constituted more than two percentage points of average monthly increases in the youth unemployment rate, compared to less than a half percentage point for prime-age individuals. Structural similarities with Spain can also be seen in contributions of the "outs" to the youth unemployment rate dynamics. The same applies to the role of increasing the youth labour force.

Yet, one key structural difference with Spain exists concerning the way the two "ins" contribute to increases in the youth unemployment rate. In the Czech Republic, the gross flow from inactivity into unemployment $\left(I_{t-1} \rightarrow U_{t}\right)$ accounted for the majority of increases in the youth unemployment rate. In contrast to that, it was the gross flow from employment into unemployment $\left(E_{t-1} \rightarrow U_{t}\right)$ that was the main driver of youth unemployment rate increases in Spain.

Our results thus signal that the difficulty to find a job faced by Czech young people at the moment of entering the labour market is likely to be the most important factor behind the observed disproportionate increases in the youth unemployment rate. In Spain, however, the key problem appears to consist in the relatively much higher exposure of young workers to job losses. The following section intends to quantify explicitly the individual labour market prospects of young people in both countries, including their gender and educational breakdowns.

\section{Comparative Analysis of Flow Transition Rates}

The differences between the flow transition rates of young and prime-age individuals are of potential policy relevance as they indicate directly the gap between labour market prospects of these two age groups. Flow transition rates are treated as a first-order Markov process, where the transitional probability of moving from previous to current labour market status depends exclusively on the previous status of an individual (Blanchard and Diamond, 1990; Gomes, 2009; Silverstone and Bell, 2010; Elsby et al. 
2011; ECB, 2012). For instance, $\lambda^{U E}=\frac{\left(U_{t-1} \rightarrow E_{t}\right)}{\left(U_{t-1} \rightarrow E_{t}\right)+\left(U_{t-1} \rightarrow U_{t}\right)+\left(U_{t-1} \rightarrow I_{t}\right)}=\frac{\left(U_{t-1} \rightarrow E_{t}\right)}{U_{t-1}}$ shows in per cent the probability to exit unemployment and become employed.

Table 5 Matrix of Flow Transition Rates

\begin{tabular}{c|ccc|c}
\hline Status in previous period $(t-1)$ & \multicolumn{3}{|c|}{ Status in current period $(t)$} & Total \\
& $E_{t}$ & $U_{t}$ & $I_{t}$ & \\
\hline$E_{t-1}$ & $\lambda^{E E}$ & $\lambda^{E U}$ & $\lambda^{E I}$ & 1 \\
$U_{t-1}$ & $\lambda^{U E}$ & $\lambda^{U U}$ & $\lambda^{U I}$ & 1 \\
$I_{t-1}$ & $\lambda^{I E}$ & $\lambda^{I U}$ & $\lambda^{I I}$ & 1 \\
\hline
\end{tabular}

Flow transition rates $\lambda$ summarised in Table 5 form a $3 \times 3$ matrix where the diagonal terms represent unchanged labour market statuses. Each row also involves two offdiagonal terms indicating the transitional probabilities. In a fully tight labour market, the off-diagonal terms equal zero. Conversely, in a totally fluid labour market with 100 per cent transitions of individuals between the statuses, the diagonal terms equal zero. These properties make the flow transition rates a useful tool for comparisons of labour market tightness/fluidity across countries, age groups and periods of time.

Nonetheless, caution is necessary in interpreting the results and comparing them to gross flow analysis presented earlier. Note that any gross flow can be expressed as a product of a given transitional probability and previous labour market stock; e.g., $\left(U_{t-1} \rightarrow E_{t}\right)=\lambda^{U E} . U_{t-1}$. It follows that the identical values of flow transition rates could conceal very different quantities of people involved in a given transition. Note that the number of unemployed is typically much lower than the number of employed. Equality of flow transition rates $\lambda^{E U}=\lambda^{U E}$ then represents a rather dramatic increase in the number of unemployed, contrary to the balanced flows between employment and unemployment that one might misleadingly assume.

Analogously, the same value of e.g., $\lambda^{U E}$ recorded for different periods, countries or age categories could again represent very different numbers of people. To avoid such stock-flow fallacy, we interpret the flow transition rates strictly as average individual prospects to change the previous labour market status in the current month. It is only in this relatively narrow sense that these rates are comparable across countries, age groups and periods of time. This also means that the values of flow transition rates alone are insufficient for concluding on the actual evolutions of labour market aggregates such as the unemployment rate. Moreover, the flow transition rates assign the same probability of changing/retaining the previous labour market status to each individual, irrespective of the duration of her/his previous status. 
Figure 1 Job loss rates $\lambda^{E U}$ in Spain and the Czech Republic (in percent; average month-tomonth individual's probability of losing job and becoming unemployed)

ES

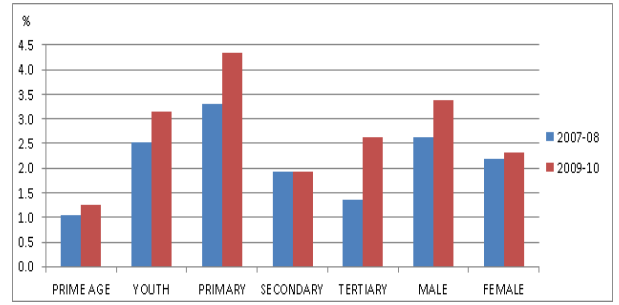

$\mathrm{CZ}$

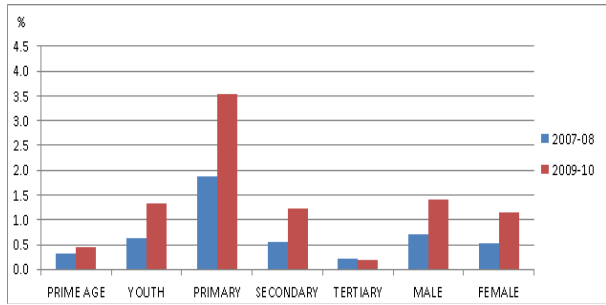

Source: EU-SILC LONGITUDINAL UDB 2009, version 4 of March 2013; EU-SILC LONGITUDINAL UDB 2011, version 1 of August 2013. Own calculations from weighted matched samples.

Note: In their first two columns, Figures 1-6 involve the comparisons of flow transition rates recorded for prime-age and young individuals. The remaining columns show the flow transition rates of youths in educational and gender breakdowns.

Figure 1 manifests that an exposure of an individual to a risk of job loss is remarkably lower in the Czech Republic than in Spain. It is a finding which holds true for both periods and in all age-, educational- and gender breakdowns. At the same time, in both countries, it confirms the presence of age-specific inequality in exposure of an individual to the risk of job loss (see the columns PRIME AGE and YOUTH). Namely, the job loss rates $\lambda^{E U}$ are persistently higher for young workers with this gap further widening in the course of Great Recession. Educational and gender breakdowns of young workers in the other columns of Figure 1 suggests that young people with primary education and young males in particular are strongly affected by this risk and its further acceleration. However, the development among the most educated young employees in Spain deserves attention, since their exposure to job loss risk has doubled. In contrast, young university graduates in the Czech Republic still enjoy a relative job security.

Figure 2 Inflow rates $\lambda^{I U}$ in Spain and the Czech Republic (in percent; average month-tomonth individual's probability of entering unemployment from inactivity)

\section{ES}

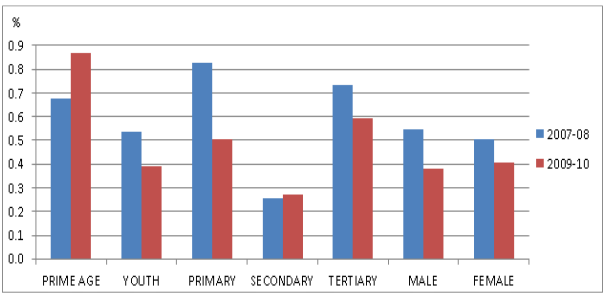

$\mathrm{CZ}$

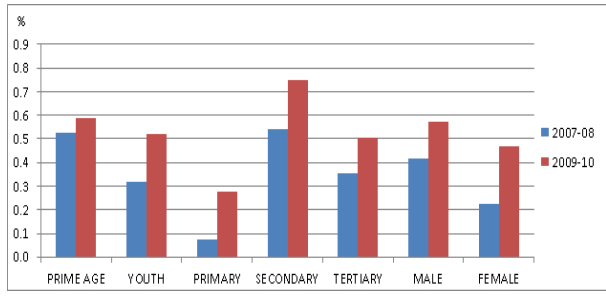

Source: EU-SILC LONGITUDINAL UDB 2009, version 4 of March 2013; EU-SILC LONGITUDINAL UDB 2011, version 1 of August 2013. Own calculations from weighted matched samples. 
According to Figure 2, an increasing exposure to unemployment risk affects the young Czech labour market entrants of all education and gender breakdowns, while in Spain the opposite tendency is apparent. Despite different country-specific developments, the young in both countries still remain relatively less affected by this type of risk in comparison to prime-age individuals. Furthermore, young people entering the labour market in Spain in 2009-2010 faced a lower risk of becoming unemployed $\left(\lambda^{I U}=0.40 \%\right)$ compared their counterparts in the Czech Republic $\left(\lambda^{I U}=0.50 \%\right)$.

A comparison with Figure 6 provides another rather surprising result: Namely, in 2009 2010, a young labour market entrant in Spain still had a higher average month-to-month probability of finding a job $\left(\lambda^{I E}=0.80 \%\right)$ than becoming unemployed $\left(\lambda^{I U}=0.40 \%\right)$. In the Czech Republic, the young people entering the labour market were confronted with quite an opposite situation, as unemployment is the more likely destiny.

Figure 3 Job finding rates $\lambda^{U E}$ in Spain and the Czech Republic (in per cent; average month-to-month individual's probability of exiting unemployment and becoming employed)

ES

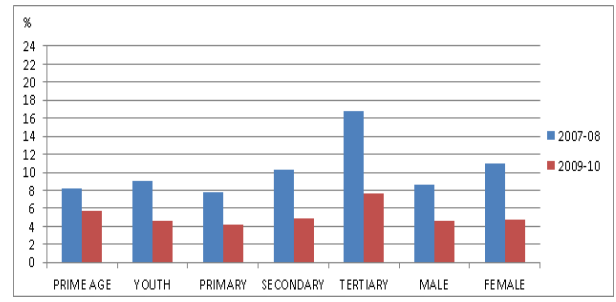

$\mathrm{CZ}$

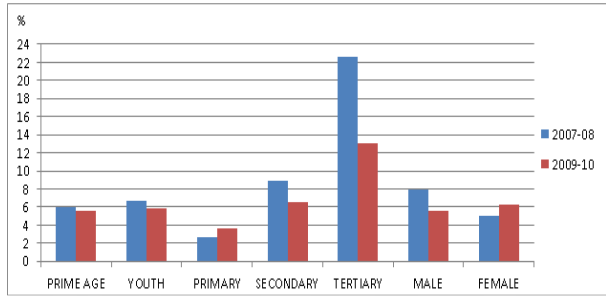

Source: EU-SILC LONGITUDINAL UDB 2009, version 4 of March 2013; EU-SILC LONGITUDINAL UDB 2011, version 1 of August 2013. Own calculations from weighted matched samples.

Figure 3 indicates that in both countries, the prospect of finding a job was initially higher among young unemployed compared to prime-age unemployed. Moreover, and perhaps surprisingly, in 2007-2008, a young unemployed Spaniard was more likely to find a job $\left(\lambda^{U E}=9.05 \%\right)$ than his or her Czech counterpart $\left(\lambda^{U E}=6.60 \%\right)$. In the second analysed period, however, this flow transition rate in Spain has deteriorated heavily and as a result, their individual prospects to find a job eventually became worse in comparison not only to the prime-age unemployed in Spain, but also to the young unemployed in the Czech Republic. Adverse development in job finding rates recorded for young unemployed people in Spain are another remarkable sign of youth labour market deterioration in the country.

According to Figure 4, the young unemployed in both countries faced relatively higher prospects to leave unemployment and move into inactivity than their prime-age counterparts in 2009-2010. The rapid acceleration in this transition probability among the young men (from 0.80 to 1.50 per cent in Spain, from 0.45 to 0.95 per cent respectively in the Czech Republic) is another common feature. Young women evince the opposite tendency as their individual prospects to leave unemployment and move into inactivity actually diminished. In Spain, the young unemployed with primary education face rapid 
increases in their prospects to move into inactivity, while in the Czech Republic this tendency is gaining in relevance for unemployed university graduates.

Figure 4 Outflow rates $\lambda^{U I}$ in Spain and the Czech Republic (in percent; average month-tomonth individual's probability of exiting unemployment and becoming inactive)

ES

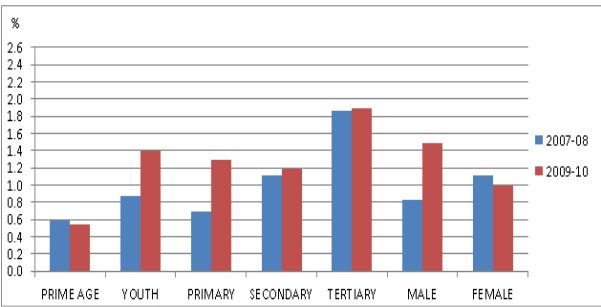

$\mathrm{CZ}$

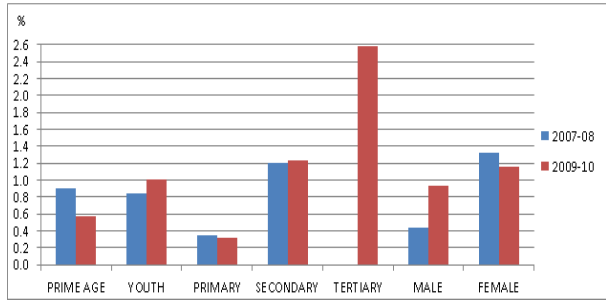

Source: EU-SILC LONGITUDINAL UDB 2009, version 4 of March 2013; EU-SILC LONGITUDINAL UDB 2011, version 1 of August 2013. Own calculations from weighted matched samples.

Figure 5 confirms young workers' higher frequency of transitions from employment into inactivity compared to prime-age ones. It is not surprising that young women in both countries show higher flow transition rates $\lambda^{E I}$ than young men. In addition to that, we see that the usual motivations behind youth transitions from employment to inactivity, such as childhood care or attempts to upgrade current education, still remain at their previous levels or even strengthened in the second analysed period. One important exemption from this tendency concerns university graduates in Spain: their flow transition rate $\lambda^{E I}$ declined quite remarkably between 2007-2008 and 2009-2010, namely from 2.75 to 1.50 per cent. From this it can be deduced that insecure prospects of smooth reentry into the labour market discourage the young university graduates in Spain from withdrawing. No similar tendency can be found among the remaining education or even gender groups in Spain and it is totally absent in the Czech Republic.

Figure 5 Flow transition rate $\lambda^{E I}$ in Spain and the Czech Republic (in percent; average month-to-month individual's probability of exiting employment and moving into inactivity)

ES

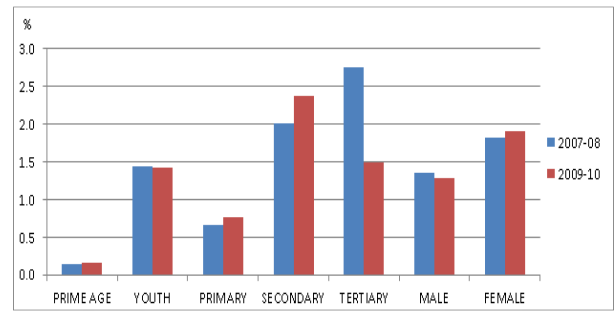

$\mathrm{CZ}$

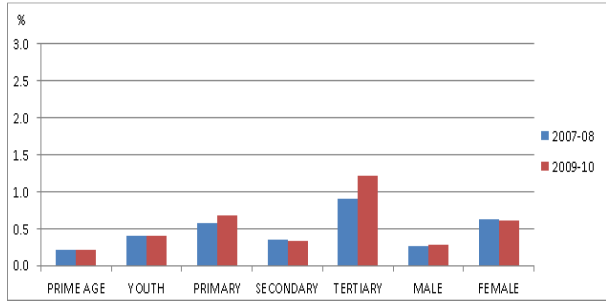

Source: EU-SILC LONGITUDINAL UDB 2009, version 4 of March 2013; EU-SILC LONGITUDINAL UDB 2011, version 1 of August 2013. Own calculations from weighted matched samples. 
Figure 6 involves transition probabilities $\lambda^{I E}$, i.e. the average chance of an inactive individual of moving into employment in the current month. As far as the first period of our analysis, in Spain this probability was higher for young people. This was in contrast with the Czech Republic, where even in the first period young labour market entrants faced relatively greater difficulties to find a job compared to prime-age individuals. But in 2009-2010 we already see that in both countries, labour market entries of young people via employment have become relatively more constrained compared to primeage individuals. Even so, in Spain the transition probability of an inactive young individual to find a job still remains higher ( 0.85 per cent) compared to the Czech Republic ( 0.40 per cent).

Figure 6 Flow transition rates $\lambda^{I E}$ in Spain and the Czech Republic (in percent; averagemonth-to-month individual's probability of entering employment from inactivity)

ES

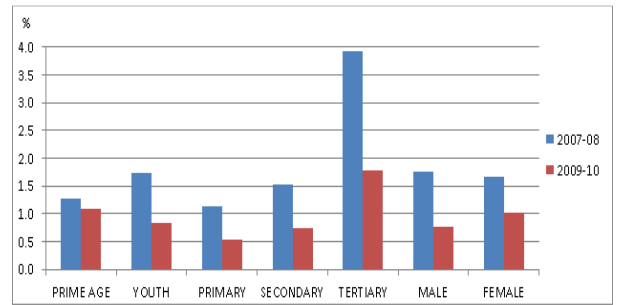

$\mathrm{CZ}$

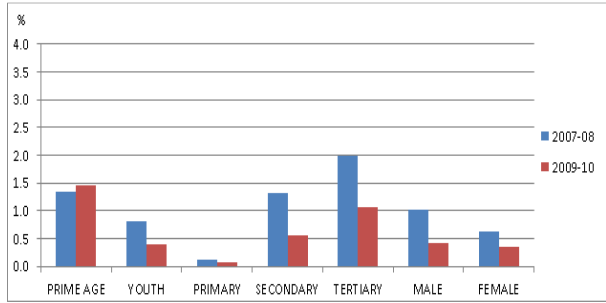

Source: EU-SILC LONGITUDINAL UDB 2009, version 4 of March 2013; EU-SILC LONGITUDINAL UDB 2011, version 1 of August 2013. Own calculations from weighted matched samples.

This actually leaves a young Czech labour market entrant with a striking one-in-two chance of receiving a job compared to young people in Spain. Although the prospects of young university graduates entering the labour market of finding a job have deteriorated heavily in both countries, in Spain their probability $\lambda^{I E}$ in 2009-2010 still represents 1.80 per cent compared to a mere one per cent in the Czech Republic. These results generally signal that the deteriorated transitions of young people from schools (or parental leave) to jobs are not necessarily the most pronounced problem faced by countries with enormously high youth unemployment. This obviously holds true only in relative terms within a given comparative analytical perspective. ${ }^{6}$

\footnotetext{
${ }^{6}$ Among other limitations, our results presented in Figure 6 do not say anything about how stable or satisfactory are the jobs held by young labour market entrants in Spain. Moreover, high job loss rates and their further increases among the young workers in Spain indeed suggest the presence of relatively high job instability.
} 


\section{Conclusion}

Both in Spain and in the Czech Republic, the relative share of young people involved in gross labour market flows between employment, unemployment and inactivity is persistently higher than that of prime-age individuals. In recent years, evidence shows a disproportionate increase in youth unemployment rate compared to prime-age unemployment rate. In Spain, this occurrence is mainly driven by the gross flow of young workers from employment to unemployment. In relative terms, this indicates that young workers in Spain are in reality much less protected against job loss than prime-age workers. This is a tendency which decisively contributes to faster growth in the youth unemployment rate in Spain. Unlike in Spain, the disproportionate increase in the youth unemployment rate in the Czech Republic is mostly generated by the gross flow of young people from inactivity to unemployment. Thus, unlike Spain, difficulties to find job faced by young people at the moment of entering the labour market seem to be the major policy challenge behind the disproportionally increasing youth unemployment rate in the Czech Republic.

These results appear to be in line with the detailed analysis of flow transition rates which maps the disproportions between the youth and prime-age labour markets from a perspective of an individual. We should underline in our main findings the fact that an exposure of an individual to the risk of job loss and unemployment is remarkably lower in the Czech Republic than in Spain, which a finding hold true in all analysed age-, educational-, and gender breakdowns. At the same time, in both countries, the job loss rates of young workers are much higher than those of prime-age workers. This gap further widened in the course of the Great Recession, a tendency which can be interpreted as a remarkable common sign of a disproportionate response of youth labour markets in both countries to economic crisis.

The findings presented above are mostly comparable to results reported by Elsby et al. (2011) for the UK. Despite different structure of data and much longer period of analysis, they also concluded that young workers were experiencing remarkably higher job loss rates compared to older workers. However, our results differ partly with respect to the outflows from unemployment. According to Elsby et al. (2011), the job finding rates of young people were over a longer run also higher than those of older workers. Our results fully confirm this tendency in the Czech Republic, while in Spain it can be observed only in the first analysed period.

Despite heavy deterioration in both countries, the results of analysing the flow transition rates from inactivity to employment still reveal that young Spaniards are relatively better off than young Czechs. This is not to say that youth transitions from inactivity to jobs in Spain are a happy story. Yet, in this particular sense, young labour market entrants in Spain still appear to have better employment prospects than those in the Czech Republic, at least in relative terms. In addition, young people entering the labour market in Spain face a lower individual risk of becoming unemployed compared to young Czechs. Finally, a young labour market entrant in Spain can still hope in a higher average month-to-month probability of finding job than becoming unemployed. In the Czech Republic, the reverse is the case, with unemployment being the more likely destiny of young labour market entrants. 
From a policy perspective, this signals that poorly performing youth labour markets with enormously high unemployment rates have not failed in all relevant respects. Currently, their development seems to be hindered predominantly by the high risk of job losses and diminishing employment prospects of the unemployed, rather than by impeded transitions from inactivity to employment. In countries with lower youth unemployment rates, unemployment policy agenda appears to be challenged by quite the opposite tendency.

\section{References}

BELL, D. N. F., BLANCHFLOWER, D. G. (2011). Young People and the Great Recession. Oxford Review of Economic Policy, Vol. 27, No. 2, pp. 241-267.

BELLMANN, L., ESTRIN, S., LEHMANN, H., WADSWORTH, J. (1995). The East German Labour Market in Transition: Gross Flow Estimates from Panel Data. Journal of Comparative Economics, Vol. 20, No. 2, pp. 139-170.

BLANCHARD, O. J., DIAMOND, P. (1990). The Cyclical Behavior of Gross Flows of US Workers. Brookings Papers on Economic Activity, Vol. 21, No. 2, pp. 85-156.

BURDA, M., WYPLOSZ, CH. (1994). Gross Worker and Job Flows in Europe. European Economic Review, Vol. 38, No. 6, pp. 1287-1315.

DIXON, R., FREEBAIRN, J., LIM, G. C. (2011). Net Flows in the U.S. Labor Market, 1990-2010. Monthly Labor Review (February), pp. 25-32.

ECB (2012). Euro Area Labour Markets and the Crisis. Structural Issues Report. Frankfurt: European Central Bank.

ELSBY, M. W. L, SMITH, J. C., WADSWORTH, J. (2011). The Role of Worker Flows in the Dynamics and Distribution of UK Unemployment. IZA DP No. 5784. Bonn: Institute for the Study of Labour.

GOMES, P. (2009). Labour Market Flows: Facts from the United Kingdom. WP No. 367. London: Bank of England.

ILO (2013). Global Employment Trends for Youth 2013. A Generation at Risk. Geneva: International Labour Office.

MCGUINNESS, S., WOODEN, M. (2009). Overskiling, job insecurity and career mobility. Industrial Relations: A Journal of Economy \& Society, Vol. 48, No. 2, pp. 26586.

SILVERSTONE, B., BELL, W. (2010). Labour Market Flows in New Zealand: Some Questions and Some Answers. Auckland: 51st Conference of the New ZealandAssociation of Economists, 30 June-2 July.

QUINTINI, G., MANFREDI, T. (2009). Going Separate Ways? School-to-Work Transitions in the United States and Europe. WP DELSA/ELSA/WD/SEM18. Paris: OECD, Directorate for Employment, Labour and Social Affairs. 